\title{
Divisão sexual do trabalho, classe e pandemia: novas percepções?
}

\author{
Thays Monticelli (https://orcid.org/0000-0002-5978-5733)' \\ Universidade Federal do Rio de Janeiro (UFRJ), Rio de Janeiro, RJ, Brasil.
}

Resumo: O objetivo do artigo é analisar como as mulheres lidaram com o período de isolamento social, sem suas tradicionais redes de apoio no processo de conciliação entre "casa" e "trabalho": trabalho doméstico remunerado, creches e escolas, arranjos familiares. Através de entrevistas semiestruturadas com mulheres pertencentes às classes médias, percebem-se poucas alterações nas dinâmicas da divisão sexual do trabalho, aumentando a sobrecarga e, consequentemente, as desigualdades vivenciadas no período. Observa-se que, a partir dessa experiência, as instituições educacionais tomam um lugar privilegiado na percepção dessas mulheres, contrapondo com uma visão menos valorativa do trabalho doméstico remunerado. Para além disso, o Estado aparece diretamente conectado com a percepção de "caos" em suas vidas, trazendo novos pontos de compreensão sobre políticas públicas voltadas ao cuidado e ao âmbito doméstico.

Palavras-chave: Divisão sexual do trabalho. Classe média. Família. Empregadoras. Pandemia.

\section{Sexual division of labor, class and pandemic: new perceptions?}

Abstract: The aim of the article is to analyze how women dealt with the period of social isolation, without their traditional support networks in the process of reconciling "home" and "work": paid domestic work, kindergartens and schools, family arrangements. Through semi-structured interviews with middle classes woman, there are few changes in the dynamics of the sexual division of labor, increasing the work overload and, consequently, the inequalities experienced in the period. It is observed that from this experience, educational institutions take a privileged place in the perception of these women, contrasting with a less appreciative view of paid domestic work. In addition, the State appears directly connected to the perception of "chaos" in their lives, bringing new points of understanding about public policies aimed at care and the domestic sphere.

Keywords: Sexual division of labor. Middle class. Employers. Pandemic.

\section{Introdução}

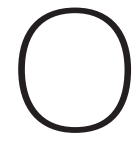

objetivo desse artigo $^{1}$ é analisar as dinâmicas que as mulheres estabeleceram cotidianamente durante o período de isolamento social - constituído como política pública para conter o avanço da Covid-19 (Brasil, 2020b) - e suas tentativas de conciliação entre as tarefas domésticas, os cuidado e as deman-
Recebido: 28.12 .20 Aprovado: 25.03 .21

I. Thays Monticelli é pós-doutoranda na Universidade Federal do Rio de Janeiro (bolsista Faperj nota 10), faz parte do Núcleo de Estudos de Sexualidade e Gênero (Neseg), Rio de Janeiro, Brasil. Orcid: 0000-00025978-5733.

$<$ tamonticelli@gmail. com>.

1. Gostaria de agradecer todos os comentários feitos no GT 20 "Gênero, família e a crise do cuidado", (Anpocs/2020), quando uma versão preliminar dos dados pôde ser debatida. Os agradecimentos também se estendem à querida Anna Bárbara Araújo, pela leitura amistosa do artigo. Por fim, agradeço os preciosos comentários das/os pareceristas ad hoc da Revista Sociedade \& Estado. 
das de seus postos de trabalho, sem o amparo das tradicionais redes que historicamente são o suporte nos processos de conciliação e delegação da divisão sexual do trabalho no Brasil: trabalho doméstico remunerado, escolas e creches e os próprios arranjos familiares (Sorj, 2004; Guimarães, 2020). Nesse sentido, essa pesquisa busca contribuir com as análises sobre a pandemia no campo das ciências sociais, a partir das análises relativas às persistentes desigualdades estruturadas na tríade "mercado, família e gênero", em um contexto totalmente atípico, que agravou e intensificou essas desigualdades do âmbito familiar, especialmente para as mulheres.

A divisão sexual do trabalho é um conceito que exprime as relações sociais entre os sexos, que, histórica e socialmente, designa o trabalho produtivo aos homens, responsabilizando as mulheres pelos trabalhos reprodutivos, condicionando um sistema de valores, hierarquias e desigualdades a partir dessa estrutura (Hirata \& Kergoat, 2007; 2021). Nota-se que os estudos do campo apontavam para algumas mudanças nos últimos anos, que giravam em torno do uso do tempo nas tarefas domésticas, da própria composição da estrutura familiar, de uma maior consciência dessas desigualdades entre os jovens e do surgimento das "novas paternidades" (Araújo et alii, 2018); contudo, essas mudanças ainda são pequenas, fragmentadas e inconstantes (Sorj \& Hitrata, 2019), situadas, muitas vezes, em grupos específicos que se conectam com as estruturas de gênero, classe e raça (Bruschini \& Ricoldi, 2009; Biroli, 2014). O fato é que as insistentes assimetrias da divisão sexual do trabalho, somadas com as poucas políticas públicas relacionadas aos cuidados e à desvalorização do trabalho reprodutivo, ainda constituem um dos maiores pilares de desigualdades de gênero no país (Sorj, 2014; Guimarães, Hirata \& Posthuma, 2020). Essa realidade reflete diretamente na interposição entre carreiras, famílias e subjetividades (Guedes, 2010; Devroux, 2011). Nesse sentido, a hipótese de que as mulheres estariam mais sobrecarregadas e que essas desigualdades se agravariam durante o período de isolamento social, é praticamente autoevidente.

De acordo com algumas pesquisas quantitativas e com levantamentos obtidos através de surveys realizados ao longo do ano, as mulheres estavam mais comprometidas com o isolamento social e ficaram mais em casa (16\%) do que os homens (9\%), aumentando mais a sensação de stress para elas (Ribeiro \& Silva, 2020). Cristina de Jesus e Luana Myrrha (2020) demostraram que, em setores da classe média, houve uma participação mais ativa dos homens nas tarefas domésticas durante a pandemia (32,4\%), mas as mulheres estavam sobrecarregadas e vivenciaram uma maior responsabilização pelo trabalho doméstico nesse mesmo período (52\%). As mulheres de classe média, em casa, passaram a trabalhar mais através do home office, precisaram dedicar mais tempo e cuidado aos/as filhos/as, estavam mais suscetíveis a perder os seus postos de trabalho, precisaram gerenciar e negociar 
aspectos da vida cotidiana com seus parceiros e administrar como seria mantida ou não - a contratação da trabalhadora doméstica remunerada, o homeschooling, os cuidados com os mais velhos e os próprios processos de flexibilização (Leão et alii, 2020; Wolff et alii, 2020).

Ressalta-se ainda que essa mesma dinâmica é produtora de uma das questões basais de desigualdade da sociedade brasileira: o trabalho doméstico remunerado. A categoria profissional de trabalhadoras domésticas foi a mais atingida pela pandemia, quando 1,2 milhões de mulheres perderam seus empregos em um ano, estando mais vulneráveis economicamente, uma vez que a informalidade tem índices altos no setor (70\%) (IBGE, 2020). De acordo com os dados da Pnad Covid19 (2021), apenas $5,9 \%$ das trabalhadoras domésticas remuneradas foram afastadas e remuneradas durante o período de isolamento social (IBGE, 2021). Além disso, algumas normativas estaduais definiram o trabalho doméstico remunerado como "serviço essencial", expondo essas mulheres a maior vulnerabilidade de contágio pelo novo coronavírus (Fenatrad, 2020). Durante esse período, essas desigualdades emergiram em episódios paradigmáticos ao longo da pandemia ${ }^{2}$, propiciando diversas indagações sobre as condições desse trabalho no país (Ávila \& Ferreira, 2020).

Nesse sentido, para além das reflexões sobre a precariedade e a vulnerabilidade que cercam essas trabalhadoras, o isolamento social ainda trouxe novas formas de viver a casa, o convívio familiar, tarefas e demandas do cuidado, sobretudo para as mulheres pertencentes às classes médias, que tiveram a experiência de passar por esse período sem suas tradicionais formas de delegação (Moreira et alii, 2020). Nesse sentido, essa pesquisa traz como interrogações norteadoras: seria possível pensar em novas percepções sobre as casas, sobre o trabalho doméstico remunerado e sobre as instituições educacionais e de cuidado, a partir dessa experiência extremada? Essas novas percepções seriam agentes de novas práticas familiares? A pandemia poderia trazer transformações sociais sobre os modelos de delegação e suas formas relacionais?

Essas perguntas se conectam tanto aos pressupostos estruturais anunciados anteriormente, quanto na própria compreensão de que esses trabalhos e consequentemente quem os faz está inserido em processos de desvalorização históricos, permeados por diversos aspectos de diferenciações e hierarquizações nas interações cotidianas entre "patroas e empregadas", "pais e professores", aprofundando desigualdades relativas aos marcadores sociais da diferença (Carvalho, 2000; Kofes, 2001).

O artigo segue com a apresentação da metodologia e do perfil socioeconômico das mulheres entrevistadas, contextualizando o campo. Em seguida, são relatadas
2. Referências como a morte de Miguel Otávio Santana da Silva, de cinco anos de idade, filho da trabalhadora doméstica Mirtes Renata Santana de Souza que trabalhava para a família Cortê Real no Recife-PE (02/06/2020). A morte de Miguel aconteceu por abandono de incapaz, uma vez que estava sob o cuidado da empregadora, enquanto a trabalhadora doméstica passeava com os cachorros da casa. Além do caso do menino Miguel, a primeira morte registrada por covid-19 no Brasil foi de uma trabalhadora doméstica remunerada na cidade do Rio de Janeiro-RJ, que se contaminou na casa de seus empregadores, recém-chegados da Europa. 
3. As videochamadas foram feitas através de ligações de vídeo por WhatsApp; o formulário socioeconômico foi aplicado através do Google Formulários. as dinâmicas que essas mulheres enfrentaram durante o período de isolamento social, a relação com seus parceiros, filhos/as e as tentativas - nem sempre bem-sucedidas - de divisão igualitária das tarefas domésticas e de cuidado. A quarta parte do artigo conta com as adaptações e percepções que essas mulheres tiveram com o trabalho doméstico remunerado, escolas, creches e com o próprio Estado. Percebe-se, assim, uma valorização maior das instituições educacionais propiciada pelo desafio de acompanhar e cuidar dos/as filhos/as em tempo integral, ao mesmo tempo que o trabalho doméstico remunerado não obteve a mesma tônica nessas narrativas, apesar de, na prática, ter sido um dos primeiros suportes a serem flexibilizados pelas mulheres entrevistadas.

\section{Metodologia e perfil socioeconômico}

O campo foi realizado através do método qualitativo, entre os meses de setembro e outubro de 2020, utilizando como técnica de pesquisa entrevistas semiestruturadas por videochamadas, além de aplicar um questionário socioeconômico para as entrevistadas ${ }^{3}$, que foram recrutadas por meio da técnica "bola de neve". Esse período garantiu que as perguntas pudessem ser feitas tanto sobre o período de isolamento social mais acirrado (abril, maio, junho e julho de 2020) como nos seus processos de flexibilização (de agosto de 2020 em diante). As entrevistas foram realizadas com base nos pressupostos metodológicos da sociologia digital (Nascimento, 2016; Miskolci, 2016), ainda que de forma principiante e em um contexto impositivo de métodos não presenciais.

Foram entrevistadas 12 mulheres, moradoras das cidades do Rio de Janeiro (RJ) e São Paulo (SP). Destacam-se alguns dados homogêneos entre elas: todas se autodeclararam brancas e tinham níveis educacionais elevados (sete delas tinham pós-graduação completa e cinco ensino superior completo). Ressalta-se que o perfil educacional foi um dos principais determinantes que possibilitaram o trabalho remoto (home office) na pandemia: $27,1 \%$ das pessoas com ensino superior completo e pós-graduação puderam estar em casa e trabalhando (IBGE, 2021).

A amostra, dessa pesquisa se torna mais diversa em termos de composição familiar e faixa etária/geração. Essas mulheres tinham, em sua maioria, idades entre 50 e 60 anos (6), seguido por mulheres entre 30 e 40 anos (4), e apenas duas entrevistadas tinham entre 20 e 30 anos. Em termos de estado civil, nove delas eram casadas, duas solteiras e uma viúva. Eram mulheres com famílias compostas por poucas pessoas, a maioria tinha entre um e dois filhos (10). Em relação à idade dos/as filhos/as, metade tinha crianças com menos de cinco anos, duas tinham filhos/as entre sete e dez anos, quatro filhos/as adolescentes (entre 12 e 18 anos) e quatro 
filhos com mais de 20 anos. Todos os/as filhos/as estavam em escolas ou creches particulares.

Das 12 entrevistadas, cinco estavam empregadas normalmente no setor privado (engenheira de telecomunicação, tradutora executiva, gerente administrativa, coordenadora do setor de recursos humanos, administradora de recursos financeiros), e três delas eram trabalhadoras informais ou autônomas (artista plástica, proprietária de um pequeno restaurante, jornalista); duas se demitiram durante a pandemia (engenheira de produção e vendedora), uma era aposentada e outra era dona de casa. Todas as 12 entrevistadas puderam fazer home office, oito parceiros também fizeram home office e outros dois não puderam fazer, uma vez que se enquadravam na categorização de "serviços essenciais".

Em termos de renda, foi perguntado quanto era a renda da entrevistada e quanto era a renda familiar, como forma de medir tanto o perfil econômico dessas famílias como as possíveis desigualdades de renda entre as mulheres e seus parceiros. Assim, o quadro de renda das mulheres entrevistadas era: quatro ganhavam até cinco salários-mínimos ( $\mathrm{R} \$ 5.225,00)$; quatro ganhavam até sete salários-mínimos ( $R \$$ 7.315,00); duas ganhavam entre dez e 15 salários-mínimos ( $R \$ 10.450,00$ a 15.675,00); duas não tinham renda.

Já a renda familiar se definiu da seguinte maneira: duas casas tinham como renda até dez salários-mínimos ( $\mathrm{R} \$ 10.450,00)$; duas casas com renda familiar entre dez e 15 salários-mínimos ( $\mathrm{R} \$ 10.450,00$ a R\$15.675,00); três casas tinham entre 15 e 20 salários-mínimos (R\$ 15.675,00 a R\$20.900,00); 5 casas com mais de 20 salários-mínimos (+ R\$20.900,00).

Do mesmo modo, os dados relativos à renda mostram uma diversidade da amostra (mulheres sem renda, mulheres com rendas baixas e mulheres com rendas altas), já em termos da renda familiar, essas mulheres podiam contar com posições mais elevadas, uma vez que a maior parte das famílias (8) tinham rendimentos maiores que 15 salários-mínimos por mês. Além disso, metade delas tinha salários mais equânimes com seus parceiros, enquanto outra metade ganhava aproximadamente $30 \%$ da composição da renda familiar. Essa lógica é importante, uma vez que pesquisas apontam como as negociações financeiras intrafamiliares se conectam diretamente com a lógica da divisão sexual do trabalho, demostrando que as negociações das tarefas de cuidado e domésticas são estabelecidas também através da responsabilidade do provimento familiar; uma vez que as mulheres, historicamente, têm rendimentos menores que os homens no mercado de trabalho, essa desigualdade é refletida dentro dos lares (Matchar, 2016; Monticelli, 2017). 
4. O seguro-

desemprego é um dos benefícios da Seguridade Social brasileira, tendo por objetivo garantir assistência financeira temporária aos trabalhadores demitidos sem justa causa e involuntariamente. Disponível em: <https://www.gov. br/pt-br/servicos/ solicitar-o-segurodesemprego>. Acesso em: 26 Mar. 2021.
Durante o primeiro ano da pandemia, metade das famílias teve suas rendas inalteradas, outra metade a renda familiar reduzida, de acordo com as respostas das informantes. Nenhuma mulher entrevistada usou algum programa de renda do governo federal durante o período, como Auxílio Emergencial, Benefício Emergencial de Preservação de Emprego e Renda ou saque do Fundo de Garantia do Tempo de Serviço (FGTS). Quanto às duas mulheres que se demitiram durante a pandemia, uma delas teve acesso ao seguro-desemprego ${ }^{4}$.

A característica fundamental para a definição do perfil das entrevistadas era o fato de elas contarem com uma trabalhadora doméstica remunerada antes da pandemia, para compreender como se estabeleceram as dinâmicas familiares sem poder contar com a delegação das tarefas domésticas e de cuidado. Assim, três das entrevistadas tinham contrato com uma trabalhadora mensalista; duas empregavam babás e dez empregavam diaristas (algumas dessas mulheres empregavam mais de uma trabalhadora). Somente as três empregadoras que contratavam mensalistas formalizavam esse contrato via Consolidação das Leis do Trabalho (CLT).

Portanto, o perfil socioeconômico dessas mulheres garante uma amostra representativa das classes médias e médias altas brasileiras, compreendendo as percepções de um grupo que historicamente consegue ter acesso aos apoios e suportes na conciliação entre a "casa" e o "trabalho", já que podem fazer a contratação desses serviços em suas vidas cotidianas. Para além disso, o perfil das entrevistadas também garante compreender quais as possíveis percepções, ou "novas" percepções, que essas mulheres possam ter a partir de uma maior proximidade com as dinâmicas de suas próprias casas e filhos/as, como podemos ver a seguir.

\section{O descobrimento da própria casa: divisão sexual do trabalho na pandemia}

Mais tempo em casa, significa mais trabalho. As mulheres entrevistadas nessa pesquisa disseram dispensar, em média, quatro horas a mais por dia nas tarefas domésticas, no cuidado e no auxílio com a educação dos/as filhos/as e dos idosos, do que antes da pandemia. Esse é um dado surpreendente, considerando-se que as alterações de tempo destinado ao âmbito residencial variam em uma proporção menor, sendo quantificados semanalmente (Bandeira \& Prelurtan, 2016; Medeiros \& Pinheiro, 2018). O número elevado de horas a mais investidos na "casa" durante a pandemia se correlaciona ao fato de muitas das mulheres entrevistadas não estarem habituadas a fazer o trabalho doméstico e, tampouco, precisavam organizar o seu tempo com tamanha atenção aos filhos/as. A falta de habilidade, ou de proximidade, com essa demanda levava as mulheres a passarem mais tempo nessas 
tarefas, uma vez que não sabiam administrá-las, não sabiam fazer, não conheciam suas próprias casas, de acordo com suas narrativas.

Entrevistada 2, 51 anos, pós-graduação completa, mora com o marido, uma filha de dez anos e passou a cuidar de um idoso na pandemia, São Paulo: Para mim o mais difícil foi eu voltar a esse ritmo, porque confesso, assim, eu tenho a diarista aqui, ela vem duas vezes por semana, né. E como o meu ritmo de trabalho é muito intenso, eu realmente... eu não olhava, eu não tinha o olhar para casa, eu não tinha noção da minha casa. Nosso olhar aqui era cozinha, coisa básica. Mas a dinâmica da casa, eu juro para você que não estava acostumada mais e surgiu a dinâmica, né. E a minha casa, nossa casa aqui, é uma casa grande, enorme. Então é uma casa, assim, que eu falei "meu deus, como que arruma isso? Eu não sei". Conclusão: essa adaptação realmente foi muito, muito difícil, né. Eu tenho a sorte do meu marido me ajudar.

Entrevistada 3, 35 anos, pós-graduação completa, mora com o marido e a filha de 4 anos, Rio de Janeiro: É, só eu que faço e uma criança pequena. Meu marido não ajuda em nada, ou seja, tem que fazer a comida, lavar a louça, acho que a maior dificuldade é com a cozinha, porque assim, limpar a casa mesmo a gente não estava fazendo, aquela limpeza geralzona não, mas a maior dificuldade foi essa de manter a cozinha limpa, de cozinhar e tudo mais.

Pesquisadora: E antes toda a parte de alimentação vocês faziam fora de casa?

Entrevistada 3: fora de casa, exatamente! Ali que pesou e como a diarista vinha uma vez por semana... a gente ainda ficava fora o dia inteiro, né. Eu vinha para casa para dormir, aí realmente eu não tinha percebido o quanto a gente suja a casa, o quanto a gente usa a casa, porque eu vinha para dormir praticamente, desde casada a minha vida sempre foi essa, com essa correria.

O desconhecimento da própria casa e de suas demandas geraram várias narrativas de "descobrimento do lar", que essas mulheres tiveram diante dessa nova realidade, até mesmo sobre o próprio tamanho de suas casas, pois disseram, por exemplo, que era grande demais para limpar, pequena demais para comportar todos ao mesmo tempo, não tinham espaço confortável para o home office, destacando uma percepção nova sobre essa vivência com a "casa". Em pesquisas anteriores, foi percebido também que o distanciamento das tarefas domésticas, entre mulheres que podiam contratar trabalhadoras domésticas, igualmente se inseriam na percepção que esse trabalho era improdutivo, desgastante, que não tinha fim, que as aprisionavam, além de interferir diretamente em suas autoestimas e nos desejos enquanto profissionais no mercado de trabalho. Eram as donas da casa, mas "odiavam" o 
trabalho doméstico (Monticelli, 2018). Nesse sentido, a imposição do isolamento social, ou o "fique em casa", apresentou para essas mulheres o próprio universo doméstico, no qual conseguiam se distanciar devido a cargas de trabalho intensivas e por uma delegação quase absoluta das tarefas domésticas, possibilitada por suas posições de classe.

De acordo com Maria de Fátima Guerra, Simone Wajnman e Bernardo Diniz (2018), a principal determinante que condiciona as contratações do trabalho doméstico remunerado no país é a condição financeira dos/as empregadores/as; majoritariamente de classe média, as famílias empregadoras brasileiras são constituídas de poucos membros e a contratação está articulada diretamente com a renda das muIheres da casa, mostrando que quanto maior seus rendimentos, mais frequente é o tipo de delegação através das mensalistas, que têm um vínculo trabalhista estabelecido cotidianamente com a casa empregadora (Guerra, Wajnman \& Diniz, 2018). Nesse sentido, as narrativas sobre uma maior proximidade com seus próprios lares nos fazem pensar nos pressupostos intuídos pela classe média em termos de estilos de vida e renda, que as afastam do trabalho reprodutivo. No entanto, a proximidade com a própria casa durante a pandemia trouxe, consequentemente, uma maior vivência com a desigualdade de gênero através das responsabilizações pelas tarefas domésticas e de cuidado.

As mulheres entrevistadas tiveram muitas dificuldades no compartilhamento das tarefas domésticas com os parceiros e filhos/as. Das 12 entrevistadas, cinco relataram que podiam contar, de forma igualitária, com a divisão das demandas da casa com seus companheiros. No entanto, essa divisão não significou que o casal teve mais tempo para se dedicar aos respectivos trabalhos ou até mesmo constituiu uma dinâmica menos intermitente entre o trabalho reprodutivo e o produtivo. Nas entrevistas surgiram relatos de casais que só conseguiam trabalhar depois que os filhos dormiam, tendo que passar a noite se dedicando aos seus trabalhos, somando uma rotina de mais de 18 horas de trabalho por dia. Em relação às entrevistas, outras sete mulheres disseram que não havia divisão das tarefas ou que conseguiam dividir minimamente com seus parceiros e filhos/as adolescentes, mas que elas ainda eram as principais responsáveis ou faziam os trabalhos mais pesados, dedicando mais tempo a essa dinâmica.

Entrevistada 7, 53 anos, ensino superior, mora com o marido e dois filhos adolescentes (13 e 17 anos), São Paulo: Tipo assim, que nem hoje, a minha rotina, eu acordei às 8 h00, hoje eu não consegui levar o lanchinho para os meninos, mas geralmente eu acordo, faço um lanchinho rápido, levo um lanchinho em cada quarto, porque eles acordam por volta de 7:10 e a outra 7:30 na EAD, eu 
deixo um lanchinho em cada quarto, aí volto e vou trabalhar. Hoje eu não consegui fazer isso, então ninguém comeu, se eu não faço, ninguém come. Aí na hora do almoço, a gente tem que correr com o almoço e eu queria limpar a casa, dar uma limpada, porque a gente faz faxina no sábado, aí todo mundo faz uma parte, mas até entender isso levou um tempo, todo mundo tem uma parte na faxina no sábado, um limpa o banheiro, o outro passa o aspirador, outro passa na mesa, eu passo os panos e a gente vai se organizando para a casa ficar apresentável, só que a limpeza não dura, você fica o tempo todo em casa e a limpeza não dura, aí eu falei: quer saber? Vou pegar a hora do almoço e vou limpar, então eu limpei rapidinho, limpei os banheiros um pouquinho, passei o aspirador na casa, aí na quarentena minha filhinha não estava bem, decidimos pegar um cão, aí tem um cão também que me demanda. E aí é uma loucura assim, mas não que eu não consiga, mas assim, é bem puxado. Eu miro, eu vejo o exemplo das minhas amigas que nunca tiveram empregada, não cara, como elas puderam por tanto tempo?

Assim, essas narrativas consolidam as "previsões" de maior sobrecarga para as muIheres durante a pandemia, que para além de uma responsabilização maior pela demanda doméstica, ainda relataram desgastes em suas vidas conjugais para o estabelecimento de uma dinâmica menos cansativa.

Entrevistada 9, 25 anos, pós-graduação completa, mora com o marido, São Paulo: Ele estava ficando bravo já de todo sábado ter a faxina, que a gente dividia, ele limpava os banheiros e eu o resto da casa. Mas ele estava ficando irritado de não aproveitar o final de semana porque ele tinha que limpar dois banheiros.

A maior parte das entrevistadas teve uma rotina de trabalho que intercalava cozinha, logins no sistema da empresa, desenho para os/as filhos/as, reuniões, banheiros, discussões com seus parceiros, almoço, ligações, limpar, faxinar, ninar, responder e-mails etc. Essa dinâmica interposta acabava por interferir em suas atividades nas empresas em que trabalhavam, uma vez que relataram as dificuldades de concentração, de mudar as atividades, de usar uma hora de almoço somente cozinhando e não comendo, do tempinho do café que era usado para brincar e dar atenção as/os filhas/os, não conseguindo "descansar".

Pesquisadora: O que mais você sentia quando estava fazendo o trabalho doméstico?

Entrevistada 9, 25 anos, pós-graduação completa, mora com o marido, São Paulo: O cansaço né, porque tem que conciliar o trabalho, a minha carreira com o trabalho doméstico era bem cansativa mesmo. E estressante, né. Que você não está com cabeça... eu 
uma hora estou vendo sinal de prédio, de internet de cliente e de repente estou lavando banheiro? Sabe? Essa questão também de ficar mudando o foco atrapalha bastante.

Felícia Picanço e Clara Araújo (2020) têm demostrado como a sensação de cansaço se correlaciona diretamente com a carga do trabalho doméstico para mulheres, influenciando as compreensões sobre a satisfação da vida em geral, além de trazer implicações em suas saúdes físicas e mentais. De acordo com as autoras, as muIheres - em uma proporção maior (43\%) - declararam que já chegavam em seus trabalhos muito cansadas, devido à carga do trabalho reprodutivo; além disso, os conflitos conjugais também se apresentavam como fator de desgaste emocional e cansaço relacionados à esfera doméstica, principalmente quando as mulheres tinham longas jornadas de trabalho, sendo a contratação do trabalho doméstico remunerado o fator que melhor amenizava esses conflitos.

Nesse sentido, é aparente o quanto a realidade da pandemia foi consideravelmente estressante para essas mulheres, que estavam vivenciando, para além de uma sobrecarga de trabalho, o desafio de administrar de forma totalmente interposta, e por vezes simultaneamente, o trabalho reprodutivo e o produtivo. É importante lembrar que os estudos feministas e de gênero têm se debruçado, há anos, na desconstrução da dicotomia "público e privado", demostrando que o "lar" não pode ser compreendido apenas como lócus dos mais singelos e harmoniosos afetos (Zelizer, 2011). O "lar", sobretudo para as mulheres, é igualmente o espaço de violências, trabalho e desigualdades (Aboim, 2012). Durante a quarentena, a ideia enrijecida dessa suposta dicotomia foi totalmente desfeita. As mulheres entrevistadas nessa pesquisa relataram que o período de isolamento social piorou suas saúdes físicas, mentais, seus momentos de lazer com a família, a relação conjugal e a vida sexual, proporcionalmente nessa sequência. Podemos dizer, assim, que a pandemia se caracteriza como momento dramático, de canseiras e desgastes intermitentes vivenciados pelas mulheres.

Ao mesmo tempo, faz-se necessário lembrar que a classe média tem acessos a mercados e consumos que podem trazer determinados confortos para suas vidas (O’Dougherty, 1998; Scalon \& Salata, 2012). Durante a pandemia, diversas reportagens foram feitas sobre o aumento da compra de eletrodomésticos, incluindo os dos setores de "inteligência artificial" (Melo, 2020). A compra dos robôs, principalmente os aspiradores de pó que fazem tudo sozinhos, foram recorrentes nas narrativas das mulheres entrevistadas.

Entrevistada 9, 25 anos, pós-graduação completa, mora com o marido, São Paulo: Ele [robô] é maravilhoso [risadas]. Ele é muito 
bom, ele custou 1.700 reais, só que assim, na época eu fiz toda uma tabela comparativa e tal para comprar bem comprado. E aí nessa marca tem vários segmentos, várias linhas de robô, tem os mais baratinhos que são fininhos e menores e tal, e até um acima do meu que também passa pano. De qualquer forma, ele varre e aspira... pode parecer que ele é bobeira, mas ele é bom porque ele te salva um tempo, enquanto ele está fazendo uma coisa, você está fazendo outra, então por exemplo, ele está passando aqui na sala, quando ele terminar você vai passar o pano na sala e ele já vai estar na cozinha, então vai uma reação em cadeia que você não precisa gastar um tempo muito grande. Assim, às vezes, você não quer limpar a casa inteira, aí enquanto você está lavando a louça, ele já está passando na sala de jantar, onde caiu alguma coisa, então salva um tempo, parece bobeira, mas é verdade.

As tecnologias do lar - muito mais discutidas pela literatura feminista internacional (Silva, 2010) -, foram percebidas como instrumentos que pudessem amenizar as desigualdades de gênero. Os eletrodomésticos além de diminuírem o tempo destinado a cada tarefa, ainda possibilitam maior facilidade do compartilhamento dos mesmos, o micro-ondas, por exemplo, faz com que cada membro da família possa esquentar seu próprio alimento, não responsabilizando uma pessoa para tal tarefa. Contudo, como nos demostra Elizabeth Silva (1998), a inserção dessas tecnologias na sociedade brasileira está condicionada pelos determinantes socioeconômicos e podem intensificar outras desigualdades.

O relato citado acima, nos demostra o quanto o robô aspirador trouxe benefícios para a vida dessa mulher, ao mesmo tempo que nos faz questionar as possibilidades de acesso a eles, uma vez que o valor desse objeto $(R \$ 1.700,00)$ é maior que o salário-mínimo nacional ( $R \$ 1.045,00)$, e representa quase duas vezes mais que a renda média das trabalhadoras domésticas remuneradas no país, antes mesmo da pandemia (Pinheiro et alii, 2019). Nessa mesma lógica, Felipe Pena e Luiz Saraiva (2019) demostram como os/as empregadores/as, muitas vezes, acreditam que as trabalhadoras domésticas remuneradas não têm conhecimentos apropriados para utilizar tais tecnologias, privando-as do consumo com receios de danificação do objeto, não estabelecendo formas mais ágeis e menos abusivas de trabalho. Nesse sentido, podemos questionar se a proximidade maior com as desigualdades vivenciadas em casa traria de fato novas percepções mais inclusivas nos modelos e sobretudo nas relações de delegação para essas mulheres.

Percebe-se que a política de isolamento social estabelecida na pandemia do novo coronavírus modificou a vida das mulheres de classe média ao aproximá-las de suas casas, das demandas domésticas e de suas próprias famílias. Essa aproximação sig- 
nificou sobrecarga de trabalho e desgastes relativos ao aprofundamento das desigualdades de gênero, ao intensificar as demandas domésticas de uma forma totalmente contínua com as demandas de seus trabalhos. Contudo, o "peso da limpeza", que estavam "carregando nas costas", não foi valorizado na mesma proporção que outras instituições de delegação e conciliação, mostrando-nos que algumas lógicas de diferenciações e hierarquizações se mantiveram em suas narrativas

\section{Casa, escola e Estado: novas percepções?}

Mais do que ter uma casa limpa, as entrevistadas afirmaram que precisavam ter os/as filhos/as na escola para poderem estabelecer uma rotina de trabalho - home office - mais tranquila, principalmente as mulheres que tinham filhos/as pequenos/ as. De tal modo, nessa pesquisa ficou aparente que a maior percepção, em termos valorativos que o período de isolamento social trouxe para essas mulheres, foi sobre o papel das creches, escolas e professoras/es, mais do que uma possível valorização do trabalho desempenhado em casa, como as faxinas, limpezas, cozinha e lavanderia.

Essa "nova" percepção se correlaciona ao fato de que os cuidados com os/as filhos/ as pequenos/as, o acompanhamento das aulas on-line e das tarefas escolares, o emocional das crianças, a saúde mental dos filhos/as adolescentes durante o isolamento social e saber utilizar o tempo de forma qualitativa com os filhos/as em casa, foram demasiadamente cansativos e angustiantes para essas mulheres.

Pesquisadora: E para você como foi a parte da educação, que antes era da escola, da creche dela?

Entrevistada 12, 38 anos, ensino superior, mora com a filha de cinco anos, Rio de Janeiro: Horrível, horrível! [risadas]. Horrível, horrível, horrível! Porque, primeiro que ela é muito pequenininha, ela não entendia que tinha que assistir aula de vídeo. E segundo, que eu não sei se eu pressionei demais, mas ela não podia escutar que tinha que assistir aula. Ela não pode ouvir falar que tem que assistir aula, nossa, virou o inferno astral da vida dela. Aí o que eu estou fazendo agora, eu pego o roteiro da escola, as folhas, apostila e faço sem ela assistir a vídeo-aula, porque ela pegou um ranço do negócio que não quer assistir as vídeo-aulas de jeito nenhum... tadinha, ter eu de professora.

Entrevistada 6, 33 anos, ensino superior, mora com o marido e dois filhos (10 meses e 4 anos), Rio de Janeiro: Nossa rede de apoio aqui é a escola, é a escola, foi difícil, foi muito difícil. Então eu senti falta da escola, se meu filho tiver na escola todos os dias, 
eu consigo dar conta da minha casa. E eu não preciso de alguém que faça isso para mim. Ah, é cansativo dobrar minhas roupas, lavar minhas roupas, guardar e limpar o chão? É, mas eu acho que faz parte da vida adulta e da vida. Não tem jeito, não tem como fugir disso ou então você fica tranquilo de ter uns dias de roupa acumulada, de ter uns dias que um monte de roupa vai estar suja, o dia que o chão vai estar sujo e tudo bem, ninguém vai morrer por causa disso também.

Pesquisadora: Depois desse tempo todo que você está olhando para a casa de um jeito tão diferente, o que mudou para você sobre as tarefas domésticas, o trabalho doméstico, com sua filha...

Entrevistada 8, 40 anos, ensino superior, mora com os pais e uma filha de nove anos, durante a pandemia passou a cuidar de mais um idoso: Olha, eu acho de questão de dar mais valor né, assim, muito mais valor ao trabalho que a L. [trabalhadora doméstica] tem, porque realmente é muito sinistro fazer coisas todo o dia, pensar e ficar fazendo. E a escola eu não sei, eu acho assim, os professores esse ano superaram de tudo, pelo menos do colégio da minha filha, sabe? Eles são os verdadeiros heróis da pandemia. Porque a questão é um milagre... eu acho, assim, complicado a escola não voltar, eles colocarem as crianças como vilãs dessa doença. Então aqui no Rio tudo já voltou, literalmente tudo. Todo mundo com uma vida assim... se você andar na rua é uma vida normal, só não tem escola, você está mostrando o que para a criança?

Assim, percebe-se que para as mulheres de classe média o cuidado com os/as fiIhos/as pequenos/as já não se estabelece primordialmente através do trabalho doméstico remunerado (Costa, 2002). É importante notar que o acesso a instituições educacionais tem índices mais elevados entre os $25 \%$ mais ricos no Brasil, onde a inserção de filhos/as em creches e escolas infantis chega a 41,1\% (Sorj, 2019). Ressalta-se, para além disso, que o número de babás contratadas não tem índices altos no país atualmente, sendo que em 2019 essa ocupação girava em torno de $10,2 \%$ dos contratos relacionados ao trabalho doméstico remunerado (Pinheiro et alii, 2019), mostrando-nos que escolas e creches, de fato, têm um peso e uma importância na realidade cotidiana das famílias de classe média, tomando um espaço importante nos processos de conciliação e delegação.

Nesse sentido, as narrativas sobre os desafios e as dificuldades com os/as filhos/as em casa tomaram um determinado "protagonismo" nas entrevistas. De acordo com o levantamento de dados quantitativos via internet, Luana Myrrha e Silvana Queiroz (2020) constataram que as babás foram as trabalhadoras que tiveram mais dificuldades em realizar o isolamento social de forma remunerada (42,2\%), sendo que muitas passaram a morar com os empregadores ou tiveram adequação da carga 
horária de trabalho. Nessa pesquisa, uma empregadora demitiu a diarista durante a quarentena, para contratar uma babá, posto que não conseguiu administrar todas as demandas do trabalho produtivo e reprodutivo com um bebê em casa.

É relevante notar que apesar das dificuldades encontradas nessa relação de cuidado com os/as filhos/as, as mulheres entrevistadas não passaram a descrever esse momento de maior proximidade em termos de "descobrimento", como o fizeram em relação à casa e às tarefas domésticas. As famílias de classe média têm, historicamente, uma política de envolvimento com as escolas que se ancora em pressupostos ideológicos, que estejam de acordo com suas posições econômicas e culturais, pensando a educação dos/as filhos/as como um plano familiar de estilos de vida, estando mais atentas na participação "família-escola" (Carvalho, 2004; Lareau, 2011).

Nessa lógica, poderíamos pensar que a maior atenção com os filhos se torna primordial em contraposição à casa, uma vez que a educação toma um lugar de importância para as classes médias, não podendo "negligenciar" ou "relativizar" esse aspecto, como fizeram com a casa. Essa "relativização" pode ser definida através de outros níveis de exigência estabelecidos sobre a qualidade da faxina, a própria percepção sobre uma casa limpa, não se importando mais com roupas amarrotadas, vidros sujos, poeira, não cozinhavam todos os dias, quando eram elas que estavam realizando esses trabalhos.

Entrevistada 4, 58 anos, ensino superior, mora com o marido, mas, na pandemia, a filha e o genro foram ficar com eles, Rio de Janeiro: Tem isso... o robô limpa o chão do banheiro, mas ele não limpa a privada, ele não limpa o box, ele não limpa nada. Mas eu também não limpo o box, então... sinceramente, o box é uma coisa, é um negócio que a gente tem que desapegar, sabe? Uma vez por mês, a moça vem, ela limpa, é uma guerra inútil, não tem como travar essa guerra do box. E vidro eu já abri mão de limpar, tudo tem um limite também. Os vidros aqui da varanda, eles não sujam muito porque aqui a gente não abre muito, não fica muito aqui e a gente abre eles com cuidado para não ficar colocando a mãozona no vidro. Mas então está tudo sempre relativamente limpo, uma vez por mês a moça vem, limpa de verdade, assim, totalmente.

No período em que as entrevistas foram realizadas, a maior parte das mulheres já tinha pedido pelo retorno da trabalhadora doméstica remunerada. Em cinco casas, a trabalhadora retornou com as atividades, mas em outro regime de carga horária e de frequência, e quatro empregadoras retornaram "normalmente" com as atividades. A maior parte dos novos arranjos foi estabelecida com o retorno da trabalha- 
dora em uma frequência menor que a anterior, como, por exemplo, uma vez a cada quinze dias ou uma vez a cada três semanas, com o valor da diária maior, já que a casa ficava mais suja - de acordo com suas narrativas. Nesse arranjo, as trabalhadoras acabavam ganhando menos que no período anterior à pandemia.

O retorno dessas trabalhadoras foi justificado nas entrevistas, de forma unânime, pelas palavras "estava muito difícil". A postura de flexibilização com essas trabalhadoras coloca em risco a vida de todas as pessoas envolvidas nessa relação trabaIhista, mas as trabalhadoras domésticas remuneradas são as mais vulneráveis, considerando o transporte público, o contato na casa das/os empregadoras/es e o fato de que essas trabalhadoras, muitas vezes, não têm acesso a uma boa infraestrutura sanitária e de saúde pública. As empregadoras entrevistadas sabiam disso, pediam para que viessem de máscara, perguntavam sobre a possibilidade de o transporte ser através do Uber ou se parentes poderiam levá-las para o trabalho. No entanto, as trabalhadoras retornaram às suas rotinas, ganhando menos e estando mais suscetíveis ao contágio pela Covid-19.

Entrevistada 6, 33 anos, ensino superior, mora com o marido e dois filhos (dez meses e quatro anos), Rio de Janeiro: Agora ela voltou, ela vem de transporte público, porque no nosso entendimento não faz diferença ela não vir de transporte público, não seria viável, não seria possível, porque a gente não teria dinheiro também para pagar o Uber ou o táxi, realmente não seria possível. Mas além disso, eu realmente acho que não fazia sentido ela não usar o transporte público, se o marido dela trabalha no Ceasa, que encontra com um milhão de pessoas, se ela vai para a casa da $\mathrm{N}$ [outra empregadora] que tem várias outras pessoas, então pela questão de contaminação a gente não ficou tão paranoico disso, dela pegar transporte público e ela estava pegando para ir para outros lugares.

A volta dessas trabalhadoras, nessas condições, é resultado da histórica informalidade, da falta de políticas públicas para ampliar a formalização e garantir melhores condições de trabalho, do processo permanente de desvalorização do trabalho doméstico remunerado (Brites, 2000; Ávila, 2009). Mas também, é o resultado de como as estruturas de classe, gênero e raça operam fortemente nessa relação contratual, fazendo com que as mulheres de classe média não tenham uma proximidade suficiente com suas próprias casas, não queiram se sujeitar a perder seu tempo com a limpeza, com o enfrentamento conjugal, com tarefas de cuidado e alimentação.

Entre as várias escolhas sobre o que deveria ser flexibilizado pela família, o trabalho doméstico remunerado logo aparecia como "fundamental": 
Entrevistada 5, 29 anos, pós-graduação completa, mora com o marido, São Paulo: A gente escolheu flexibilizar na faxina. [...] Eu prefiro viver com uma fruta que não está madura porque eu comprei pelo aplicativo, do que ter que arrumar a casa no final de semana.

É importante dizer que as escolas e creches estavam fechadas de acordo com as normativas governamentais, o que impossibilitava as "escolhas" das famílias sobre a volta dos/as filhos/as para as creches e escolas, ao passo que as trabalhadoras domésticas remuneradas trabalhavam em suas casas, majoritariamente, como informais - aspecto que sustenta uma rede de barganhas e negociações entre as exigências das empregadoras e as necessidades das trabalhadoras (Monticelli, 2017). Assim, por mais que a trabalhadora doméstica remunerada não estivesse na narrativa dessas mulheres como "as heroínas da pandemia", rapidamente foram chamadas de volta para "apagar o fogo" de suas casas.

Além disso, outro ponto de destaque nessas entrevistas se relaciona com as escolhas do que seria flexibilizado ou não em suas vidas. O Estado brasileiro, sob a presidência de Jair Messias Bolsonaro, eleito em 2018, teve grandes dificuldades políticas e ideológicas de enfrentamento ao novo coronavírus, passando por diversas crises ministeriais, atritos entre o governo federal e os governos estaduais, negacionismos, além de uma profunda crise econômica (Campos, 2020; Bridi, 2020). Isso estabeleceu um processo de individualização frente aos cuidados e ao próprio enfrentamento da pandemia, resultando para cada indivíduo encontrar as respostas para sua crise financeira, sobre as medidas a serem flexibilizadas, os cuidados com o contágio, além das escolhas e decisões morais em relação ao cuidado com o outro. Esse contexto aparece diretamente nas narrativas das mulheres entrevistadas e em suas dinâmicas com a divisão sexual do trabalho e do cuidado com os/as filhos/as, estando as normativas políticas presente em quase todas as entrevistas.

Pesquisadora: Como foi tentar estabelecer uma divisão minimamente mais igualitária?

Entrevistada 7, 53 anos, ensino superior, mora com o marido e dois filhos adolescentes, São Paulo: Então, tentar eu tento todos os dias, eu continuo tentando, mas não funciona, não funciona, porque eu acho que, realmente, a mulher... além de eu, às vezes, trabalhar oito, nove horas por dia, eu fico bem sobrecarregada. Igual agora, eu estou conversando com você, se eu não levantar e fizer uma janta, não acontece. Aí eu surto uma, surto duas, surto três, sabe? É muita coisa que eu tenho de fazer, quer dizer, eu sou a professora de ginástica do filho, eu sou a professora de inglês da menina, eu sou a empregada que lava, passa e cozinha, meu trabalho... entendeu? É punk, é punk... se as outras pessoas têm 
filhos que ajudam maravilhosamente bem, maridos que ajudam maravilhosamente bem, esse não é o meu caso... e esse governo que não faz nada, na-da! É um desespero por dia. A conta não bate, nessas horas que você se pergunta: quem mandou queimar o sutiã, cara? Quem mandou queimar o sutiã? Porque o governo não está fazendo nada.

Entrevistada 2, 51 anos, pós-graduação completa, mora com o marido, uma filha de dez anos, São Paulo: Então, assim, esse período que a mamãe esteve aqui, eu vou falar para você que eu acho que a mamãe mais me ajudou do que eu ajudei ela, é uma coisa impressionante, porque, principalmente em relação à casa, ela sempre ajudava, passava uma vassourinha, coisas leves, coisas que ela podia fazer e que era bom ela fazer. [...] O difícil era o relacionamento, assim, porque muda o ritmo né... essa parte de comunicação, isso é complicado, não foi uma e não foram duas, meu marido ficava bravo, né. Então isso foi uma coisa muito, muito difícil, a ponto de uma coisa boba: televisão. Gente, aquele começo da pandemia, a nossa decisão foi "não vamos ver jornal, não aguento mais ficar vendo aquelas notícias". Então a gente via outras coisas, mas ela [mãe] adora ver o Jornal Nacional, ela adora! E o meu marido não gostava que visse, por quê? Para não ficar vendo aquelas notícias que só traziam coisa ruim, vamos ver um filme. Eu já não aguentava mais ver o governo não fazendo nada, assistia jornal era morte e fila de auxílio emergencial.

Entrevistada 3, 35 anos, pós-graduação completa, mora com o marido e a filha de quatro anos, Rio de Janeiro: Eu vi muita discussão elitizada em favor de que as aulas continuem suspensas, eu vejo com esse ajudante do meu marido que mora na favela, o ajudante de cozinha dele. Ele tem uma filha pequena, o quanto ele sofreu das aulas estarem suspensas. E as pessoas falam "ah, mas é horrível a condição da escola pública". Que ótimo, vamos abrir esse debate, vamos ter sempre esse debate da qualidade da escola pública, mas não é porque a escola pública tem uma qualidade ruim que as aulas não devam voltar, porque essas crianças ficaram em creches parentais, totalmente improvisadas, com pessoas que não têm nenhuma formação em pedagogia e nada, sujeitas à violência, sujeitas a todo tipo de insegurança mesmo.

O Estado aparecia na narrativa dessas mulheres por meio dos questionamentos sobre o retorno às aulas, na vulnerabilidade das escolas públicas, na eficácia - ou não - do isolamento social enquanto política pública, como condicionantes que aprofundavam ansiedades, angústias, tristezas e medos, essas mulheres não suportavam ter que acompanhar o noticiário e traçar parâmetros de cuidado a partir da instabilidade política, mesmo as que ideologicamente acompanhavam o atual governo. Assim, durante o governo de Jair Bolsonaro, as mulheres não só estavam mais vulneráveis, como passaram a não contar com Estado para assegurar um iso- 
lamento social seguro, com decisões consolidadas sobre o processo educacional e para os próprios processos de flexibilizações em seus trabalhos, como foi percebido nas entrevistas realizadas. Isso significa dizer que essas mulheres conectavam diretamente o "caos" de suas vidas, com as insuficiências do Estado. E, talvez, o que essa pesquisa nos mostra é que essa percepção foi possibilitada através da experiência da quarentena, em casa, responsabilizando-se por diversas tarefas, sem poder delegar as demandas do âmbito doméstico.

A ausência do Estado, que aparece de forma nítida para essas mulheres, na correlação direta com suas vidas cotidianas, tornou-se uma política de governo. No dia 9 de dezembro de 2020, o governo federal decretou "A estratégia nacional de fortalecimento dos vínculos familiares", que tem um teor familista e que responsabiliza a família pelo cuidado dos filhos, dos idosos, das pessoas com deficiência, que preze pelo "o reconhecimento do valor social do trabalho doméstico e de cuidado como essenciais para o desenvolvimento da família e da sociedade" (Brasil, 2020a: 4). Esse decreto foi concebido pelo Comitê Interministerial, constituído pelo Ministério da Mulher, da Família e dos Direitos Humanos, pela Casa Civil, pelos Ministérios da Educação, da Cidadania e da Saúde. É importante ressaltar que esse decreto está em total consonância com a política neoliberal e conservadora da extrema direita proferida pelo atual governo desde o processo eleitoral (Klein, Carmo \&Tavares, 2020), resultando em um enfrentamento das políticas de igualdade de gênero, impondo uma lógica de fortalecimento da "família tradicional" (Biroli, 2020).

Nesse sentido, podemos perceber que as desigualdades vivenciadas pelas mulheres, ao longo da pandemia, não vão ter um caminho de possíveis soluções via políticas públicas. Essas mulheres vão continuar sobrecarregadas entre as demandas domésticas, familiares e suas posições no mercado de trabalho, seguindo com seus modelos tradicionais de delegação, que no Brasil se dá de forma individualizada, informal e precária. É importante ressaltar que essa lógica, intensificada através das diretrizes do atual governo, não corrobora para que "novas percepções", ou até mesmo "novas práticas", sejam estabelecidas diante dessas desigualdades.

Essa pesquisa demostrou que o período de pandemia - sobretudo o de isolamento social - trouxe novas dinâmicas, para as mulheres de classe média, sobre suas casas e famílias; mas essa proximidade não estabeleceu uma correlação direta com novas formas de pensar seus mecanismos de delegação. A "casa" foi relativizada para elas mesmas, mas continuaram com os níveis de exigência quando esse trabalho era feito pela trabalhadora doméstica remunerada; não pensaram tampouco em formas mais inclusivas de contratação via CLT, que pudessem garantir mais proteções à essas trabalhadoras. Ao passo, que as escolas e creches, já internalizadas como 
instituições constituintes de suas posições de classe, apareceram de forma mais valorizada em suas narrativas. Como anunciado anteriormente, a correlação direta do que estava acontecendo em suas vidas - principalmente em termos das demandas domésticas - com o Estado, surge a partir do momento que o acesso aos modelos de delegação foi privado, possibilitando novos aspectos a serem vislumbrados em termos de compreensão de políticas públicas destinadas ao âmbito doméstico e ao trabalho reprodutivo, pelas classes médias.

\section{Considerações finais}

Este artigo buscou analisar como as mulheres de classe média vivenciaram o período de isolamento social durante a pandemia do novo coronavírus, compreendendo que a política do "fique em casa" pressupõem determinadas relações de cuidados familiares, que desconsideram as diversas desigualdades relativas ao âmbito doméstico, e mais que isso, as próprias configurações de poder intrafamiliares que refletem nos processos de conciliação e delegação no Brasil.

Percebe-se que essas mulheres tiveram uma convivência com suas próprias casas, passaram a "conhecer de perto" as demandas e os trabalhos que o âmbito doméstico exige para estabelecer a sensação de bem-estar, para criar condições minimamente harmônicas intrafamiliares e para dar sustentação em termos de cuidados com filhos/as e idosos/as, demostrando que a pandemia não trouxe, necessariamente, novas práticas ou transformações na estrutura e na dinâmica familiar em relação à divisão sexual do trabalho. Essa convivência, extrema e obrigatória, trouxe mais sobrecarga e desigualdade para essas mulheres, influenciando diretamente em seus postos de trabalho, além dos desgastes causados por uma rotina interposta e intermitente entre trabalho reprodutivo e produtivo.

Contudo, essa realidade não foi agente de "novas" percepções sobre o trabalho doméstico remunerado e as instituições educacionais. As mulheres entrevistadas passaram a relativizar as exigências com as tarefas domésticas, com padrões de limpeza de como deveriam estar suas casas, no momento em que passaram a fazê-las. No início da pandemia, algumas hipóteses foram levantadas em relação a essa proximidade, correlacionando-a com uma possível demissão em massa das trabalhadoras domésticas remuneradas, uma vez que as mulheres de classe média passariam a ver essa contratação como dispensável. De fato, essa pesquisa nos mostra justamente o contrário. O trabalho doméstico remunerado não se tornou dispensável, sendo um dos primeiros a serem flexibilizados, trazendo diversas vulnerabilidades para essas trabalhadoras. A proximidade com a casa tampouco trouxe "novas" percepções sobre esse trabalho em si, as exigências feitas para essas 
trabalhadoras, a valorização de seus trabalhos e uma relação menos hierarquizada não foi estabelecida. Ao passo que as instituições educacionais, tais como creches e escolas, foram compreendidas como os verdadeiros apoios na vida cotidiana dessas mulheres, reafirmando uma ligação que a classe média tem com a política educacional.

Esse quadro, de "poucas" novidades, talvez seja reflexo da realização de uma pesquisa de campo feita na urgência dos fatos, em que mudanças ainda não sejam percebidas ou que não tiveram o tempo suficiente para serem concretizadas; ou talvez, essas percepções não se alteraram tanto porque o trabalho em si não mudou, a pandemia não trouxe transformações nas condições do trabalho produtivo e reprodutivo para essas mulheres, condicionando em novas percepções e práticas entre a "casa" e o "trabalho", reafirmando e intensificando as desigualdades já existentes.

O que essa pesquisa traz como ponto instigante é a compreensão dessas desigualdades propiciadas pelas insuficiências do Estado. A classe média, por conseguir fazer os processos de delegação e conciliação por contratações de trabalhadoras domésticas, através da rede privada de ensino, solucionando essas questões de forma mais individualizada, foi barrada de seu acesso a essa estrutura pela política de isolamento social. Isso fez com que o "governo" estivesse na narrativa de quase todas as entrevistadas, conectando os aspectos de desigualdades de suas vidas cotidianas, com a ideia da necessidade de fazer políticas públicas relacionadas aos cuidados e ao âmbito doméstico, sem compreendê-las como destinadas somente às classes populares. Se a pandemia não trouxe novas práticas ou transformações em como se estruturam a lógica da divisão sexual do trabalho, ela pode trazer novas formas de pensar as políticas do âmbito doméstico e do cuidado.

\section{Referências}

ABOIM, Sofia. Do público e do privado: uma perspectiva de gênero sobre uma dicotomia moderna. Revista Estudos Feministas, v. 20, n. 1, p. 95-117, 2012.

ARAÚJO, Clara et alii. Evolução das percepções de gênero, trabalho e família no Brasil: 2003-2016. In: ARAÚJO, Clara et alii. Gênero, família e trabalho no Brasil do século XXI: mudanças e permanências, p.1-81. Rio de Janeiro: Gramma, 2018.

ÁVILA, Maria Betânia de Melo. O tempo do trabalho das trabalhadoras domésticas: tensões entre dominação/exploração e resistência. Recife: Editora UFPE, 2009. 
ÁVILA, Maria Betânia; FERREIRA, Verônica. Trabalho doméstico remunerado: contradições estruturantes e emergentes nas relações sociais no Brasil. Psicologia e Sociedade, v. 32, n. 2, Belo Horizonte, 2020.

BANDEIRA, Lourdes Maria; PRELURTAN, Renata Barreto. As pesquisas sobre o uso do tempo e a promoção da igualdade de gênero no Brasil. In: FOUNTOURA, Natália; ARAÚJO, Clara. Uso do tempo de gênero, p.43-59. Rio de Janeiro: UERJ, 2016.

BIROLI, Flávia. Gênero, "valores familiares" e democracia. In: BIROLI, Flávia; MACHADO, Maria das Dores Campos; VAGGIONE, Juan Marco. Gênero, neoconservadorismo e democracia, p.135-187. São Paulo: Boitempo, 2020.

. O público e o privado. In: MIGUEL, Luis Felipe; BIROLI, Flávia. Feminismo e política: uma introdução, p. 31-46. São Paulo: Boitempo, 2014.

BRASIL. Decreto n. 10.570, de 9 de dezembro de 2020a. Institui a estratégia nacional de fortalecimento dos vínculos familiares e seu Comitê Interministerial. Diário Oficial da República Federativa do Brasil, Brasília, 10 Dez. 2020.

BRASIL. Lei n. 13.979, de 6 de fevereiro de 2020b. Dispõe sobre as medidas para enfrentamento da emergência de saúde pública de importância internacional decorrente do coronavírus responsável pelo surto de 2019. Diário Oficial da República Federativa do Brasil, Brasília, 07 Fev. 2020.

BRIDI, Maria Aparecida. A pandemia Covid-19: crise e deterioração do mercado de trabalho no Brasil. Estudos Avançados, São Paulo, v. 34, n. 100, 2020.

BRITES, Jurema. Afeto, desigualdade e rebeldia: bastidores do serviço doméstico. Tese (Doutorado em Antropologia) - Instituto de Filosofia e Ciências Humanas, Universidade Federal do Rio Grande do Sul, Porto Alegre, RS, 2000.

BRUSCHINI, Maria Cristina A.; RICOLDI, Arlene Martinez. Família e trabalho: difícil conciliação para mães trabalhadoras de baixa renda. Cadernos de Pesquisa, v. 39, n. 136, p. 93-123, São Paulo, 2009.

DEVREUX, Anne-Marie. A teoria das relações sociais de sexo: um quadro de análise sobre a dominação masculina. Sociedade e Estado, v. 20, n. 3, p. 561-584, 2011.

CAMPOS, Gastão Wagner de Sousa. O pesadelo macabro da Covid-19 no Brasil: entre negacionismos e desvarios. Trabalho, Educação e Saúde, v. 18, n. 3, 2020.

CARVALHO, Maria Eulina Pessoa. Modos de educação, gênero e relações escola-família. Cadernos de Pesquisa, v. 34, n. 121, p. 41-58, 2004. 
Relações entre família e escola e suas implicações de gênero. Cadernos de Pesquisa, v. 2, n. 110, p. 143-155, São Paulo, 2000.

COSTA, Suely Gomes. Proteção social, maternidade transferida e lutas pela saúde reprodutiva. Revista Estudos Feministas, v. 10, n. 2, p. 301-323, 2002.

FEDERAÇÃO NACIONAL DAS TRABALHADORAS DOMÉSTICAS (FENATRAD). Fenatrad protesta contra decreto que determina a atividade doméstica como serviço essencial durante a pandemia da Covid-19. 2020. Disponível em: <https://fenatrad. org.br/2020/05/08/fenatrad-protesta-contra-decreto-no-para-que-determina-a-atividade-domestica-como-servico-essencial-durante-a-pandemia-da-Covid-19/>.

GUIMARÃES, Nadya Araújo. O cuidado e seus circuitos: significados, relações e retribuições. In: GUIMARÃES, Nadya Araújo; HIRATA, Helena. O gênero do cuidado: desigualdades, significações e identidades, p.91-128. Cotia, SP: Ateliê Editorial, 2020.

GUIMARÃES, Nadya Araújo; HIRATA, Helena; POSTHUMA, Anne. El cuidado: su formas, relaciones y actores (reflexiones a partir del caso no Brasil). In: GUIMARÃES, Nadya Araújo; HIRATA, Helena (Orgs.). El cuidado en America Latina, p.77-119. Buenos Aires: Medifé, 2020.

GUEDES, Moema de Castro. A inserção dos trabalhadores mais escolarizados no mercado de trabalho brasileiro: uma análise de gênero. Trabalho, Educação e Saúde, v. 8, n. 1, p. 55-75, 2010.

GUERRA, Maria de Fátima Lage; WANJMAN, Simone; DINIZ, Bernardo. Quem contrata trabalhadoras domésticas diaristas e mensalistas no Brasil? Anais do XXI Encontro Nacional de Estudos Populacionais (Abep). 2018

HIRATA, Helena; KERGOAT, Danièle. A atualidade da divisão sexual e centralidade do trabalho das mulheres. Revista de Ciências Sociais - Política \& Trabalho, v. 1, n. 53, p. 131-143, 2021.

Novas configurações da divisão sexual do trabalho. Cadernos de Pesquisa, v. 37, n. 132 , p. 595-609, 2007.

INSTITUTO BRASILEIRO DE GEOGRAFIA E ESTATÍSTICA (IBGE). Pesquisa nacional por amostra de domicílio Covid19. 2021. Disponível em: <https://covid19.ibge.gov.br>.

Pesquisa nacional por amostra de domicílios contínua quarto trimestre de 2020. 2020. 
JESUS, Cristina Jornada de; MYRRHA, Luana Junqueira Dias. Os afazeres domésticos antes e depois da pandemia: desigualdades sociais e de gênero. Programa de Pós-Graduação em Demografia da Universidade Federal do Rio Grande do Norte. Disponível em: <https://demografiaufrn.net/2020/07/16/afazeres-domesticos-antes-e-depois/>.

KLEIN, Charles; CARMO, Milena; TAVARES, Alessandra. Between "us" and "them": political subjectivities in the shadows of the 2018 brazilian election. Revista de Antropologia, v. 63, n. 2, 2020.

KOFES, Sueli. Mulher, mulheres: identidade, diferença e desigualdade na relação entre patroas e empregadas domésticas. Campinas, SP: Editora Unicamp, 2001.

LAREAU, Annette. Unequal childhoods: class, race, and family life. California: University of California Press, 2011.

LEÃO, Natália et alii. Trabalho e vida das mulheres na pandemia. In: OLIVEIRA, Dalila Andrade; POCHMANN, Marcio. A devastação do trabalho: classe do labor na crise da pandemia, p. 289-311. Brasília: Gráfica e Editora Positiva, 2020.

MATCHAR, Emily. Homeward bound: why woman are embracing the new domesticy? New York: Simon\&Shuster, 2016.

MEDEIROS, Marcelo; PINHEIRO, Luana. S. Desigualdades de gênero em tempo de trabalho pago e não pago no Brasil, 2013. Sociedade e Estado, v. 33, n. 1, p. 161187, 2018.

MELO, Alexandre. Brasileiros compram mais eletrodomésticos durante a quarentena: cresce venda online de aspirador de pó e liquidificador. Valor Investe/OGlobo. 2020. Disponível em: <https://valorinveste.globo.com/objetivo/gastar-bem/noticia/2020/04/17/em-casa-brasileiro-compra-mais-eletrodomesticos.ghtml>.

MISKOLCI, Richard. Sociologia digital: notas sobre pesquisa na era da conectividade. Contemporânea-Revista de Sociologia da UFSCar, v. 6, n. 2, 2016.

MONTICELLI, Thays Almeida. Cuidado e poder: as relações do trabalho doméstico remunerado através da cultura doméstica. In: TAMANINI, Marlene et alii (Orgs.). O cuidado em cena: desafios políticos, teóricos e práticos. Florianópolis: Editora Udesc, 2018.

"Eu não trato empregada como empregada": empregadas e os desafios do trabalho doméstico remunerado. Tese (Doutorado em Sociologia) - Programa de Pós-Graduação em Sociologia, Universidade Federal do Paraná, Curitiba, PR, 2017. 
MOREIRA, Lisandra Espíndula et alii. Mulheres em tempos de pandemia: um ensaio teórico-político sobre a casa e a guerra. Psicologia e Sociedade, Belo Horizonte, v. 32, n. 2, 2020.

MYRRHA, Luana Junqueira Dias; QUEIROZ, Silvana Nunes. Pesquisa aponta que metade dos empregadores mantiveram remuneração enquanto os empregados domésticos estavam afastados durante a pandemia da Covid-19, 2020. Disponível em: <https://demografiaufrn.net/2020/07/06/projeto-domesticas-ufrn-primeiros-resultados/>.

NASCIMENTO, Leonardo Fernandes. A sociologia digital: um desafio para o século XXI. Sociologias, v. 18, n. 41, p. 216-241, Porto Alegre, 2016.

O'DOUGHERTY, Maureen. Auto-retratos da classe média: hierarquias de "cultura" e consumo em São Paulo. Dados, v. 41, n. 2, p. 411-444, Rio de Janeiro, 1998.

PENA, Felipe Gouvêa; SARAIVA, Luiz Alex Silva. Ressignificação, consumos e silêncios da cozinha doméstica. Organizações \& Sociedade, v. 26, n. 90, p. 558-578, Salvador, 2019.

PICANÇO, Felícia; ARÁUJO, Clara. Conflitos desiguais: homens e mulheres na articulação casa-trabalho no Brasil. Século XXI: revista de ciências sociais, v. 9, n. 3, p. 720-749, 2020.

PINHEIRO, Luana et alii. Os desafios do passado no trabalho doméstico do século XXI. Reflexões para o caso brasileiro a partir dos dados da Pnad contínua. Textos para Discussão. Rio de Janeiro: Ipea, 2019

RIBEIRO, Ludmila; SILVA, Bráulio. O coronavírus, as mulheres e o lar: uma combinação explosiva? Dilemas: Revista de Estudos de Conflito e Controle Social. Reflexões da pandemia, 2020

SCALON, Celi; SALATA, André. Uma nova classe média no Brasil da última década? O debate a partir da perspectiva sociológica. Sociedade e Estado, v. 27, n. 2, p. 387407, 2016.

SILVA, Elizabeth. Tecnologia e vida doméstica nos lares. Cadernos Pagu, v. 10, n. 2, p. 21-52, 1998.

SILVA, Elisabeth. Maids, machines and morality in Brazilian homes. Feminist Review, v. 94, n. 1, p. 20-37, 2010.

SORJ, Bila; No Brasil, novas perspectivas. In: MARUANI, Margaret. Trabalho, logo existo: perspectivas feministas, p. 103-113. Rio de Janeiro: FGV Editora, 2019. 
Socialização do cuidado e desigualdades sociais. Tempo Social, v. 26, n. 1, p. $123-128,2014$.

Reconciling work and family: issues and policies in Brazil. Geneva: International Labour Organization. 2004. Disponível em: <https://www.ilo.org/wcmsp5/ groups/public/---ed_protect/---protrav/---travail/documents/publication/wcms_ travail_pub_8.pdf>.

SORJ, Bila; HIRATA, Helena. Introdução. In: MARUANI, Margaret. Trabalho, logo existo: perspectivas feministas. Rio de Janeiro: FGV Editora. 2019.

WOLFF, Cristina Scheibe et alii. Pandemia na necroeconomia neoliberal. Revista de Estudos Feministas, v. 28, n. 2, 2020.

ZELIZER, Viviana A. A negociação da intimidade. Petrópolis, RJ: Editora Vozes, 2011. 
